\title{
Parents' opinion on pediatric physiotherapy and the physical therapy
}

\author{
Marianna Stavropoulou ${ }^{1}$, Hristara-P Alexandra ${ }^{2 *}$, Thomas Apostolou ${ }^{3}$, Paris Iakovidis ${ }^{4}$, Kamparoudi G Maria ${ }^{5}$ and Trevlakis Manolis ${ }^{6}$ \\ ${ }^{1}$ Postgraduate Program, International Hellenic University, Greece \\ ${ }^{2}$ Head of the Postgraduate Program, International Hellenic University, Greece \\ ${ }^{3}$ Assistant Professor of Physiotherapy, International Hellenic University, Greece \\ ${ }^{4}$ Professor of implementations of Physiotherapy at I.H.U, International Hellenic University, Greece \\ ${ }^{5}$ Postgraduate Program, Pediatric Physiotherapy, International Hellenic University, Greece \\ ${ }^{6}$ Academic scholar of Physiotherapy, International Hellenic University, Greece
}

\begin{abstract}
Introduction: Pediatric physiotherapy deals with the evaluation and rehabilitation of disorders that occur in infants to adolescents. It helps children with motor disabilities to improve their gross mobility and functionality in order to maximize their independence, autonomy and security, as well as to properly prepare their child so that they can successfully participate in their social environment and activities of daily living.

Purpose: The main purpose of this study was to record the opinion of parents about pediatric physiotherapy and the physiotherapist.

Method: The study involved 37 parents of children with motor disabilities. The research was conducted at the Neuro Physio Kids Physical Therapy Center Konstantinou Karamanlis 60 Thessaloniki.

Results: $78 \%$ of the sample of parents / guardians who participated in the survey responded that they liked the physiotherapy process, and $79 \%$ believed that physiotherapy helps improve their child's functionality.

Conclusion: In our sample, parents / guardians of children with motor disorders who follow a physiotherapeutic intervention program, many researchers like the process of physiotherapy and are actively involved in its implementation as they are encouraged by the physiotherapist. The question of whether physiotherapy helps to improve a child's functionality and to facilitate their day-to-day life is an only negative answer, possibly due to the seriousness of the problem. The rest at a very high rate give positive answers and are aware of the positive effect of physiotherapy. Further research on a larger number of parents / guardians of children with motor disorders is recommended.
\end{abstract}

\section{Introduction}

Families with children with motor disabilities are called upon to deal with a variety of problems from day to day childcare, treatment, child education, social inclusion and, most importantly, their independence. Their support from specialist health professionals (psychologists, therapists, doctors, etc.) is essential for psychological support, guidance, treatment and education so that the parent can cope alone $[1,2]$. From the first stage of diagnosis and listening to the parent to diagnose their child, they need the support of specialist professionals to understand the condition, answer questions and be trained in how to support their child [3-7]. Parent education in the day-to-day care of the child is necessary to meet the daily needs such as bed-wetting, walking, etc. Both parents and professionals (physiotherapists, occupational therapists, physicians) develop and maintain a beneficial and balanced relationship to create a solid foundation around their child's therapeutic and supportive role in dealing with the child with the disorder [7].

Numerous studies report that poor 'inadequate communication' is the most serious parent / patient complaint and in particular lack of information. But, even when professionals try to communicate, their terminology is often misunderstood or forgotten over time. Lack of communication can also be a means of retaining the expert's power. Listening to a parent is likely to be of great importance in the communication process $[8,9]$.

Pediatric physiotherapy deals with the evaluation and rehabilitation of disorders that occur in infants to adolescents. It helps children with motor disabilities to improve their gross mobility and functionality, with the aim of maximizing their independence, autonomy and safety, as well as properly preparing their child so that they can successfully participate in their social environment and in the activities of daily life.

The pediatric physiotherapist aims to encourage and improve the child's ability to move and function in the most normal way [10]. Physiotherapeutic intervention improves the behavioral and movement characteristics that make the child functional and improve

*Correspondence to: Hristara-Papadopoulou Alexandra, Head of the Postgraduate Program, International Hellenic University, Greece, Tel: +6942222445; Email: alekpap@phys.teithe.gr

Key words: pediatric physiotherapy, parents' opinion of pediatric physiotherapy and physiotherapist

Received: February 09, 2020; Accepted: February 21, 2020; Published: February 25,2020 
their quality of life $[11,12]$. Normal movements cannot be obtained if the child remains in abnormal positions and moves in a pathological manner, so pediatric physiotherapy helps the child to change abnormal positions and movements in order to gain a better quality of functional activities and therefore a better quality of life.

The physiotherapist evaluating the areas and motor skills in which each child has difficulty, design the appropriate treatment plan, focusing on improving each child's developmental abilities and teaches parents how to manage their child's issues. The cooperation and active involvement of parents in the treatment of their child is crucial in the therapeutic program, in order to educate and learn for themselves how to participate in their child's therapeutic activities, transferring them to their daily lives [10].

\section{Materials and methods}

Thirty-seven (37) parents of children (7 of whom were their father and 30 of them mothers) with motor impairment participated in the study, which was conducted in Thessaloniki at the Neuro Physio Kids Physical Therapy Center Konstantinou Karamanlis 60 Thessaloniki. The children of age range from 9 months to 18 years old boys and girls with motor disabilities and were diagnosed with the following conditions: cerebral palsy, developmental abnormality, myopathy / myasthenia, individual cases involving diagnoses such as neuropsychological delays, general hypertension with psychomotor delay, leukoencephalopathy and hyperkinesia. These diseases are chronic and physiotherapeutic methods and techniques have been applied for many years.

\section{Protocol}

A special questionnaire was used as a measuring tool, completed by parents of children with motor impairments. Questionnaires were collected through personal interviews during March - April 2018 and descriptive statistics and correlation analysis were performed.

\section{Statistical analysis}

Initially, variables were investigated for basic characteristics, frequencies, extreme values, etc. Descriptive methods were initially applied to evaluate the results of the study and then independent tests were performed with the help of IBM SPSS Statistics 23. The variables of the sample as well as the number of cases per category led to nonparametric case tests. Kruskal-Wallis test was used to test for mean differences in dichotomous variables. In all cases the level of statistical significance was $p<0.05$.

\section{Results}

Our sample consisted of 37 parents of children (7 fathers and 30 mothers) with motor disorders following a physiotherapy intervention. $67.6 \%$ of children receive physiotherapy at least 2 to 3 times a week (Table 1) and 95\% started physiotherapy immediately (Table 2).

It is also characteristic that many researchers like the process of physiotherapy and are actively involved in its implementation as they are encouraged by the physiotherapist (Table 3). Physiotherapy is performed by $89.2 \%$ in a private clinic (Table 4 ).

The question of whether Physiotherapy helps to improve a child's functionality and if it makes their daily lives easier, the exception is only one negative answer, possibly due to the seriousness of the problem. The rest at a very high rate give positive answers and are aware of the positive effect of physiotherapy (Table 5).
Table 1. Frequency of Physiotherapy

\begin{tabular}{|c|c|c|}
\hline $\begin{array}{c}\text { Frequency of } \\
\text { Physiotherapy }\end{array}$ & People & percentage \\
\hline Every day & 1 & $(2.7 \%)$ \\
\hline Twice / three times a week & 25 & $(67.6 \%)$ \\
\hline Once a week & 10 & $(27 \%)$ \\
\hline Rarely & 1 & $(2.7 \%)$ \\
\hline Total & 37 & $(100 \%)$ \\
\hline
\end{tabular}

Table 2. Beginning of physiotherapy

\begin{tabular}{|c|c|c|}
\hline $\begin{array}{c}\text { Started physiotherapy } \\
\text { immediately after referral }\end{array}$ & People & Percentage \\
\hline Yes & 35 & $(94.6 \%)$ \\
\hline No & 2 & $(5.4 \%)$ \\
\hline Total & 37 & $(100.0 \%)$ \\
\hline
\end{tabular}

Table 3. Views on Physiotherapy

\begin{tabular}{|l|c|c|}
\hline Views on Physical Therapy Positive Answers & People & Percentage \\
\hline Actively participate in conducting therapeutic session & 19 & $(51.4 \%)$ \\
\hline Do you like the process of attending physiotherapy session & 28 & $(75.7 \%)$ \\
\hline You would prefer to use this time in another way & 13 & $(35.1 \%)$ \\
\hline $\begin{array}{l}\text { Physiotherapist encourages your active participation in } \\
\text { physiotherapy session }\end{array}$ & 23 & $(62.2 \%)$ \\
\hline $\begin{array}{l}\text { Do you think that physiotherapy alone is enough for the } \\
\text { functional development of your child }\end{array}$ & 15 & $(40.5 \%)$ \\
\hline $\begin{array}{l}\text { Further homework needed } \\
\begin{array}{l}\text { It needs to be combined with some complementary therapy } \\
\text { (horse therapy, hydrotherapy etc) }\end{array}\end{array}$ 18 & $(43.6 \%)$ \\
\hline
\end{tabular}

Table 4. Applied Physiotherapy

\begin{tabular}{|c|c|c|}
\hline Physical Therapy & People & Percentage \\
\hline House & 3 & $(2.7 \%)$ \\
\hline Private clinic & 34 & $(89.2 \%)$ \\
\hline Total & 37 & $(100.0 \%)$ \\
\hline
\end{tabular}

Table 5. Benefits of Physiotherapy

\begin{tabular}{|l|c|c|}
\hline $\begin{array}{l}\text { Do You Know the Positive Impact of Physical Therapy on } \\
\text { the Physical Fitness and therefore on Your Child's Health }\end{array}$ & People & Percentage \\
\hline I know perfectly & 19 & $(51.4 \%)$ \\
\hline I know quite a few & 17 & $(45.9 \%)$ \\
\hline I don't know at all & 1 & $(2.7 \%)$ \\
\hline Total & 37 & $(100.0 \%)$ \\
\hline
\end{tabular}

Table 6. Physiotherapy education physical therapy

Apply at home specialized exercises, position changes, activity training at the suggestion of your physiotherapist

\begin{tabular}{|l|c|c|}
\hline If yes how many hours do you work per week & Yes & No \\
\hline$>7$ hours a week & $6(85.7 \%)$ & $1(14.3 \%)$ \\
\hline $6-7$ hours weekly & $11(84.6 \%)$ & $2(15.4 \%)$ \\
\hline$<4$ hours per week & $9(90.0 \%)$ & $1(10.0 \%)$ \\
\hline Total & $26(86.7 \%)$ & $4(13.3 \%)$ \\
\hline
\end{tabular}

Usually both parents work at home physiotherapy and most of them spend between 6-7 hours a week (min.6).

When asked what they consider to be a priority in their child's recovery, $61 \%$ said they could walk and move alone or with aids (Table 7).

When asked if they understand the reasons for their child's functional limitation, $73 \%$ said yes (Table 8). 
Table 7. Primary goal

\begin{tabular}{|l|c|c|}
\hline $\begin{array}{l}\text { What is considered a priority in your child's recovery } \\
\text { Positive Responses }\end{array}$ & People & Percentage \\
\hline Can eat without help & 11 & $(30.6 \%)$ \\
\hline Can be washed without help & 11 & $(30.6 \%)$ \\
\hline Can sit (alone or with auxiliary means) & 8 & $(22.2 \%)$ \\
\hline Standing upright (alone or with auxiliary means) & 11 & $(30.6 \%)$ \\
\hline Walking and moving (alone or with auxiliary means) & 22 & $(61.1 \%)$ \\
\hline Improvement of external appearance (eg posture) & 18 & $(50.0 \%)$ \\
\hline Speaking & 10 & $(27.8 \%)$ \\
\hline
\end{tabular}

Table 8. Reasons of limitations

\begin{tabular}{|l|c|c|}
\hline $\begin{array}{l}\text { Understand the Reasons of Your Child's Functional } \\
\text { Limitation }\end{array}$ & People & Percentage \\
\hline Yes, I understand & 27 & $(73.0 \%)$ \\
\hline Yes, I understand the basics & 8 & $(21.6 \%)$ \\
\hline Yes, I partially understand & 2 & $(5.4 \%)$ \\
\hline Total & 37 & $(100.0 \%)$ \\
\hline
\end{tabular}

\section{Discussion}

Pediatric physiotherapy pays particular attention to the harmonious and good therapist-child-parent relationship, so a good communication and continuous cooperation between them is essential [13-15]. The physiotherapist needs the parent's cooperation to achieve effective treatment as the outcome depends directly on the active involvement, support and confidence of the parents so that their child can benefit from it [16]. Both parents and professional physiotherapists need to create and maintain a beneficial and balanced relationship in order to establish a solid background around their child's therapeutic and supportive role in dealing with the disorder.

Good cooperation and communication between the therapist and the parent become essential for the child's progress and treatment [10]. Parenting is a very important source of help in the treatment of children with dysfunctions as the benefits gained through therapeutic intervention can be enhanced at home. Parents can apply some of the home therapy in the form of toys and thereby enhance the teaching of the therapist, thereby complementing that of the physiotherapist [2]. Further research on a larger number of parents / guardians of children with motor disorders is recommended.

\section{Suggestions}

Based on the results of the present research, the following is suggested:

The physiotherapist must:

- provides professional information and advice to parents and family, so that the parent is properly informed about what help they can ask and what they can expect from the treatment.
- be accessible and friendly in order to gain the trust of the parent and the child.

- shares and demonstrates understanding of parents' emotions, managing their reactions and being able to restore balance.

- tries to attract and encourage parents to attend the therapy session and to educate them on how to apply therapeutic techniques at home.

\section{References}

1. Bennett T, Nelson DE, Lingerfelt BV, Davenport-Ersoff, C (1992) Family centered service coordination, Facilitating Family-centered training in early intervention. $A Z$ : Communication Skill Builders 143-171.

2. Effgen SK, Chiarello LA (2000) Physical Therapist education for service in early intervention. Infants Young Child 12: 63-76

3. Blacher J (1984) "Sequential stages of parental adjustment to the birth of o child with handicaps: fact or artefact?" Severely Handicapped Young Children and their Families: Research in Review Mental Retardation 22: 55-68

4. Weisbren SE (1980) Parents reactions after the birth of a developmentally disabled child", American Journal of Mental Deficiency 84: 345-351

5. Davis H, Buchan L, Choudhury, P. Ali (1994) "Supporting families of children with chronic illnessor disability: multi-cultural issues" in P. Mittler and H. Mittler (eds) Innovations in Family Support for People with Learning Disabilities. Working with Families of Children with Special Needs: Partnership and Practice

6. Cunningham CC, Davis H (1985) Working with Parents: Frameworks for Collaboration, Milton Keynes Open University Press.

7. Cunningham CC (1985) Training and education approaches for parents of children with special needs British Journal of Medical Psychology 58: 285-305.

8. Davis, H (1993) Counselling Parents of Children with Chronic Illness or Disability, Leicester British Psychological Society

9. Fost N (1981) Counselling families who have a child with a severe congenital anomaly. Paediatrics 67: 321-325. [Crossref]

10. Hristara-Papadopoulou Alexandra, Georgiadou Athena, Papadopoulou Ourania, (2014) Physiotherapy in Paediatrics.

11. Bailey DB, McWilliam, PJ (1993) The search for quality indicators. Handbook of Early Childhood Intervention 3-20.

12. Bailey DB, McWilliam RA, Darkes LA, Hebbeler K, Simeonsson, et al. (1998) Family outcomes in early intervention: A framework for program evaluation and efficacy research. Exceptional Children 64: 313-328

13. Turnbull A, Blue Banning M, Turbiville V, Park J (1999) From Parent Education to Partnership Education: A call for a Transformed Focus. Topics in Early Childhood Special Education 19: 164-171.

14. Turnbull AP, Turnbull HR (1993) Group action planning: Families, friends, and professionals. Unpublished manuscript. The University of Kansas, The Beach Center on Families and Disability, Lawrence.

15. Turnbull AP, Turnbull HR (2001) From the Old to The New Paradigm of Disability and Families: Research to Enhance Family Quality of Life Outcomes. KU Scholar Works

16. Roush J, Hanison M, Palsha, S (1991) Family-centred early intervention: The perceptions of professionals. American Annals of the Deaf 136: 360-366.

Copyright: (C2020 Stavropoulou M. This is an open-access article distributed under the terms of the Creative Commons Attribution License, which permits unrestricted use, distribution, and reproduction in any medium, provided the original author and source are credited. 